\title{
Tecnologias Móveis na Inclusáo Escolar e Digital de Estudantes COM Transtornos de Espectro Autista ${ }^{1}$ \\ Mobile TeChNologies in EDUCATion and Digital InCLUSion of StUdents WITH AUTISM SPECTRUM DISORDERS
}

\author{
Lucila Maria Costi SANTAROSA² \\ Débora CONFORTO ${ }^{3}$
}

\begin{abstract}
RESUMO: com foco nas políticas públicas inclusivas, a relação entre estudantes com Transtorno de Espectro Autista e dispositivos móveis foi problematizada para discutir os limites e as possibilidades da configuração tecnológica 1:1 em apoiar processos de inclusão escolar e digital na rede pública brasileira de ensino. Metodologicamente, caracteriza-se como uma pesquisa qualitativa de enfoque exploratório e explicativo, epistemologicamente apoiada na teoria sócio-histórica e conduzida por dois grandes questionamentos: (i) Os dispositivos móveis apresentam interface acessível a sujeitos com Transtornos de Espectro Autista? (ii) Que movimentos foram desencadeados pela mediação dos dispositivos móveis para potencializar a inclusão sociodigital de sujeitos com Transtornos de Espectro Autista? A partir dos dados coletados foi possível analisar as fragilidades e as potencialidades da interação de três sujeitos de pesquisas, estudantes dos anos iniciais da Educação Básica em processo de alfabetização, pela interface da tecnologia móvel. O comportamento refratário dos sujeitos de pesquisa em relaçâo ao laptop educacional pode ser justificado pelos problemas de acessibilidade tecnológica associada ao dispositivo móvel, muitos deles potencializados pelas especificidades do Transtorno de Espectro Autista: interface pouco amigável, de difícil compreensão pelo grau de abstração e pela complexidade do sistema operacional, com suas múltiplas escolhas e configuraçóes. $\mathrm{Na}$ interação com o tablet foi possível constatar um manuseio amigável e intuitivo, pois a manipulação com o objeto ocorre de forma direta e natural, com o toque do dedo. A arquitetura dessa tecnologia permite seu uso em diferentes lugares e posiçóes, uma resposta positiva à hiperatividade e para qualificar estratégias de mediação pedagógica.
\end{abstract}

PALAVRAS-CHAVE: Educação Especial. Empoderamento. Política de inclusão social. Informática e educação. Autismo.

\begin{abstract}
Autism Spectrum Disorders and mobile devices was examined in order to discuss the limits and possibilities of the technological configuration 1:1 for supporting education and digital inclusion programs in Brazilian public schools. Methodologically, this was a qualitative research, with exploratory and explanatory approaches. Epistemologically, the study was supported by the socio-historic theory and guided by two major questions: (i) Do mobile devices have accessible interfaces for individuals with Autism Spectrum Disorders? (ii) What movements were triggered by the mediation of mobile devices for enhancing the socio-digital inclusion of individuals with Autism Spectrum Disorders? From the collected data, we could observe frailties and potential for interaction for the three research subjects. The participants were attending the first years of Elementary School, during literacy process with the use of mobile devices. We concluded that the subjects' resistance towards the educational laptop can be justified by accessibility problems associated to the mobile device, many of which increased by the specificities of Autism Spectrum Disorders: poor user-friendly interface, difficult to understand due to the level of abstraction, and complex operational system, with its multiple choices and configurations. The interaction with the tablet showed a more friendly and intuitive use, as handling the object occurs more directly and naturally with fingers touching the screen. The architecture of this technology allows the use in different places and positions, a positive response to hyperactivity as well as qualifying strategies for pedagogical mediations.
\end{abstract}

KEYWORDS: Special Education. Empowerment. Social Inclusion Policy. Informatics and education. Autism.

1 http://dx.doi.org/10.1590/S1413-65382115000400003

Os resultados da investigação apresentada neste artigo configuram-se como um recorte da pesquisa "Estudo sobre o Processo de" Mediação entre Pessoas com Deficiência em Comunidades de Inclusão Digital (Etapa II - 2013-2016), aprovada pelo Comitê de Ética da Plataforma Brasil (CAAE 17827613.2.0000.5347), sob a coordenaçăo da Dra. Lucila Maria Costi Santarosa e desenvolvida pela equipe de pesquisadores do Núcleo de Informática na Educação Especial, da UFRGS.

${ }^{2}$ Universidade Federal do Rio Grande do Sul, Núcleo de Informática na Educação Especial (NIEE). Porto Alegre, RS, Brasil. lucila.santarosa@ufrgs.br

${ }^{3}$ Universidade Federal do Rio Grande do Sul, Núcleo de Informática na Educação Especial (NIEE). Porto Alegre, RS, Brasil. deboraconforto@gmail.com 


\section{INTRODUÇÃo}

Historicamente, obstáculos têm sido impostos a pessoas com deficiência, dificultando, e até mesmo impossibilitando, o acesso a benefícios sociais, como saúde e educação. As tecnologias digitais podem operar como recursos de empoderamento, ampliando a possibilidade de integração social.

Empoderamento, conceito presente nas agendas empresariais, foi trazido para o cenário educacional por Paulo Freire, entre tantas outras expressōes, como "Educação Bancária", "Cultura do Silêncio", sempre colocadas em discussão ao afirmar a capacidade de transformação humana. Empoderar é a ação pela qual indivíduos, comunidades e organizaçóes obtêm recursos que lhe permitam ter voz, visibilidade, influência, capacidade de ação e de tomada de decisão.

A importância que esse conceito assume quando o viés da análise passa a ser colocado na perspectiva da diversidade humana foi ratificada por Irina Bokova, Diretora-geral da Organização das Naçóes Unidas para a educação, a ciência e a cultura (Unesco), ao afirmar que empoderar pessoas com deficiência significa empoderar a sociedade como um todo (UNESCO, 2014).

$\mathrm{O}$ acesso aos instrumentos que permitem provocar práticas de empoderamento não ocorre de forma automática, em particular para os sujeitos que se encontram em desvantagens físicas, sensoriais, cognitivas, como também para aqueles em condição de vulnerabilidade socioeconômica. Os governos ao estruturar e gerenciar sistemas externos aos indivíduos e às organizaçóes devem forjar estratégias para que as práticas de apropriação de recursos de empoderamento sejam dadas também às pessoas com deficiência.

A escola brasileira afirma-se como uma instituiçáo de acolhimento da diferença e de ruptura com as ações educativas cerceadas pela rígida demarcação de tempos e espaços para o aprender. Por meio de políticas públicas inclusivas, a diversidade humana e os dispositivos móveis (laptops e tablets) começam a imprimir as possibilidades e os desafios relacionados à presença de estudantes com deficiência na escola regular, como também de experienciar de conceitos de conectividade, de portabilidade, de flexibilidade, de pertencimento e de customização.

Ao ser tecido pelo conceito da diferença, o processo educativo aponta, na mesma medida, para a necessidade de problematizar os recursos educacionais que são disponibilizados para as escolas. Pesquisas no campo da Informática na Educação Especial têm ilustrado a capacidade das tecnologias digitais quando acessíveis em impulsionar novas práticas de empoderamento para professores e estudantes, com e sem deficiência (SANTAROSA; CONFORTO; VIEIRA, 2014). 


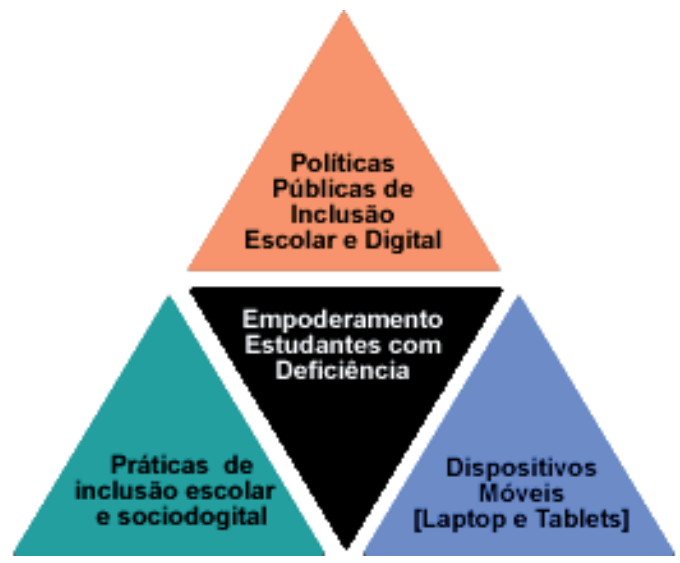

Figura 1 - Organograma do plano investigativo.

Fonte: Adaptado do Relatório Geral Unesco (2014)

Objetivando delinear as práticas de inclusão escolar e sociodigital desencadeadas pela interface de dispositivos móveis - laptops e tablets, pesquisadores do Núcleo de Informática na Educação Especial (NIEE), da Universidade Federal do Rio Grande do Sul (UFRGS), inspirados pelo escopo do Relatório Geral da Unesco (2014, p.19), passaram a olhar os dados coletados pelo imbricamento e complementaridade de três elementos representados na Figura 1. O elemento desencadeador para projetar o plano de pesquisa foi conduzido por políticas públicas afirmativamente inclusivas, açóes governamentais que se colocam como meios fundamentais para criar contextos socioculturais e econômicos para operar sob a lógica da equidade. Ao ser estabelecia essa prerrogativa, conquista sentido diferenciar as expressōes igualdade e equidade.

Igualdade, representada pelo sinal aritmético de igual, remete à promoção de situaçôes idênticas, uniformes e equivalentes para todas as pessoas. A palavra equidade faz referência à capacidade de apreciar e julgar com retidáo, justiça e igualdade diferentes açóes e contextos sociais, produtos e processo de açôes humanas. A equidade prima por analisar com imparcialidade cada caso para que não haja desigualdades e injustiças.

Políticas públicas que arquitetam um processo educacional que não afirma o conceito de equidade produzirão uma escola impassível às diferenças, tratando igualmente os desiguais. Como advertem as palavras de Bourdieu (1999, p.53), "[...] a igualdade formal que pauta a prática pedagógica serve como máscara e justificativa para a indiferença no que diz respeito às desigualdades reais $[\ldots] "$.

O princípio constitucional brasileiro que garantiu a universalidade de acesso, contemporaneamente, assegurada também para o aluno com deficiência, não deve ser fragilizado pela busca da homogeneidade que tradicionalmente tem sustentado as práticas educativas que tratam igualmente os desiguais. As políticas públicas inclusivas, foco de discussão deste artigo, tem sua relevância construída na possibilidade de analisar a ação governamental como promotora de estratégias que alavanquem contextos legislativos, regulatórios e inclusivos (Quadro 1) em prol do reconhecimento e da valorização da diversidade humana. 


\begin{tabular}{|l|l|} 
Contexto & $\begin{array}{l}\text { Políticas públicas que oficialmente passam a reconhecer a existência da diversidade humana. } \\
\text { Ex.: Política Brasileira de Educação Especial na Perspectiva da Educação Inclusiva (Brasil, } \\
\text { 2007). }\end{array}$ \\
$\begin{array}{ll}\text { Contexto } \\
\text { Regulatório }\end{array}$ & $\begin{array}{l}\text { Açóes governamentais que projetam estratégias inovadoras para a promoção de uma sociedade } \\
\text { com equidade social. Ex.: Modelo de Acessibilidade estabelecido pelo e-MAG. (Brasil, 2011) e } \\
\text { a Políticas de Cotas. }\end{array}$ \\
$\begin{array}{ll}\text { Contexto } \\
\text { Inclusivo }\end{array}$ & $\begin{array}{l}\text { Açóes locais que permitem revelar o grau de compromisso de setores públicos e privados.Con- } \\
\text { quistam maior significado quando não são pontuais ou restritas a tempos e espaços específicos. } \\
\text { Ex.: Atendimento Educacional Especializado (AEE) e Salas de Recursos Multifuncionais. }\end{array}$ \\
\hline
\end{tabular}

Quadro 1 - Contextos legislativos, regulatórios e inclusivos.

Fonte: Adaptado Relatório Geral Unesco (2014)

Apoiado nessas problematizaçóes, um objeto de investigação foi estabelecido para analisar os limites e as possibilidades de açóes decorrentes de políticas públicas educacionais em relação a estudantes com Transtorno de Espectro Autista matriculados em instituiçóes de ensino que vivenciam as influências de açóes governamentais de inclusão sob duas dimensōes: 1) a escolar, desenhada pela Política Nacional de Educação Especial na perspectiva da Educação Inclusiva; 2) a digital, pelo programa "Um computador por Aluno (UCA)", permitindo que redes públicas de ensino pudessem vivenciar os conceitos de mobilidade e de conectividade característicos da configuraçáo 1:1. Os conceitos de mobilidade e de conectividade projetam no tempo e no espaço escolar a possibilidade ampliar e potencializar a conquista da fluência digital ao: 1) romper com a lógica da escassez imposta pelo modelo de informática educativa, centrado no na configuraçáo do Laboratório de Informática (CONFORTO, 2014); 2)permitir o deslocamento escola-família-escola para a tecnologia digital, estendendo os benefícios sociais de acesso à informação e a construção de conhecimento para além dos muros da instituição escolar.

\section{Método}

A análise conduzida pela equipe do NIEE assumiu como foco de estudo a construção de conhecimento no ascendente campo de saber que cerca a investigaçáo da acessibilidade tecnológica e da inclusão sociodigital para a relação produzida entre dispositivos móveis e alunos com deficiência. Como objetivo geral de pesquisa foi estabelecido mapear os reflexos de políticas públicas inclusivas, no âmbito escolar e digital, analisando a emergência de movimentos de empoderamento para estudantes com Transtorno do Espectro Autista quando em interação com dispositivos móveis.

O processo de concretizaçáo do objeto de estudo foi conduzido por duas grandes questôes de pesquisa: 1) Os dispositivos móveis apresentam interface acessível e usável para sujeitos com Transtornos de Espectro Autista? 2) Que movimentos foram desencadeados pela mediaçáo dos dispositivos móveis para potencializar a inclusão sociodigital de sujeitos com Transtornos de Espectro Autista?

Metodologicamente, esta investigaçáo caracteriza-se como uma pesquisa qualitativa de enfoque exploratório e explicativo, empregando a técnica de análise textual discursiva, conforme proposta por Moraes (2003). Para a coleta de dados foram utilizadas a observação direta, 
a análise documental, as entrevistas e as dinâmicas de grupos focais, realizadas no periodo de março a dezembro de 2013.

Epistemologicamente apoiadas na teoria sócio-histórica, as estratégias que conduziram a coleta e a análise dos dados buscaram destacar o dinamismo entre o pesquisador, os participantes e o contexto inclusivo, afirmando-os como elementos dialeticamente implicados. Ratificando o pensamento de Vygotsky (1999), uma trajetória de pesquisa foi construída para discutir um fenômeno essencialmente humano, o que exigiu que os resultados fossem analisados no processo de sua implementação e nas mudanças desencadeadas pela configuração tecnológica 1:1.

Para discutir os limites e as possibilidades da utilização de dispositivos móveis junto a estudantes com Transtorno de Espectro Autista em inclusão foi estabelecido como corpus de investigação três escolas participantes do programa brasileiro Um Computador por Aluno (UCA) que responderam positivamente aos critérios: 1) ser escola inclusiva; 2) possuir sala de recursos multifuncionais; 3) revelar uma efetiva utilização do dispositivo móvel e 4) ter no corpo discente estudantes com deficiência regularmente matriculados.

A escolha dos professores em cada instituição de ensino participante foi determinada, em primeiro lugar, pela aceitação do educador em colaborar com a pesquisa e, em segundo, pelo tipo de deficiência do aluno sob sua responsabilidade pedagógica. Esse segundo critério foi importante para mapear um conjunto mais amplo e com significativo de tipos de deficiência em interação com o dispositivo móvel, possibilitando uma coleta de informaçóes mais qualificada e refinada.

Para conceber um processo efetivo e contínuo de coleta e de registro de informaçóes nas instituiçóes que participaram do universo pesquisado, foi desenhada a figura do agente de observação, com o perfil: 1) docente de classes inclusivas, mediador do processo de aprendizagem junto a alunos com deficiência ou 2) profissionais atuantes na Sala de Recursos Multifuncionais (SRM) responsáveis pelo Atendimento Educacional Especializado (AEE) de estudantes com deficiência em processo de inclusão escolar. Ao desenhar o papel do agente de observação, confirmamos a indissociável relação que deve acompanhar toda a ação de docência, a do professor/pesquisador.

O profissional que atuava junto ao aluno com deficiência assumiu a responsabilidade de executar uma observação de enfoque participante, um processo de coleta de informaçóes que: 1) supóe a interação pesquisador/pesquisado; 2) implica em saber escutar, ver, fazer uso de todos os sentidos para aprender aspectos relacionados à mediação técnica e pedagógica e à interaçáo intra e interpessoal; 3) estabelece uma rotina de pesquisa, promovendo um exame de dados mediante a manutenção de um diário de campo.

Todo o processo de interação com o professor que atuou como agente de observação foi estruturado na modalidade presencial e não presencial, utilizando para essa última o ambiente digital Eduquito ${ }^{4}$. Essa estratégia de pesquisa possibilitou uma mediação mais pontual com cada educador participante, realizando as correçôes necessárias para qualificar o registro de

\footnotetext{
${ }^{4}$ Ambiente Digital de Aprendizagem desenvolvido pela equipe do NIEE/UFRGS, contando com apoio do Conselho Nacional de Desenvolvimento Científico e Tecnológico (CNPq) do Ministério de Ciência e Tecnologia (MCT).
} 
observação dos estudantes com deficiência em processo de inclusão escolar e tecnológica, como também o apoio na postagem dos respectivos relatórios de observação e dos diários de campo.

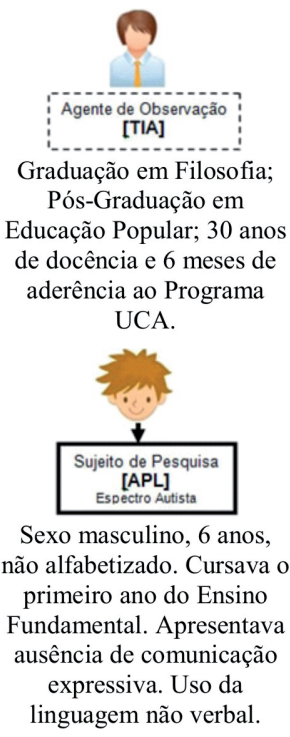

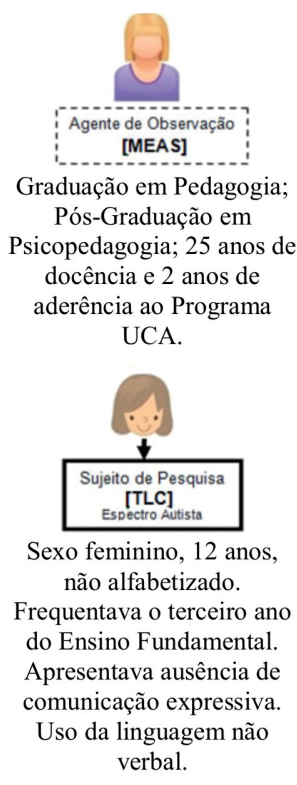

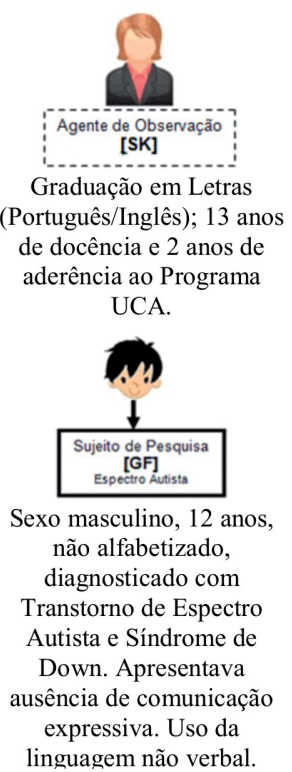

linguagem não verbal.

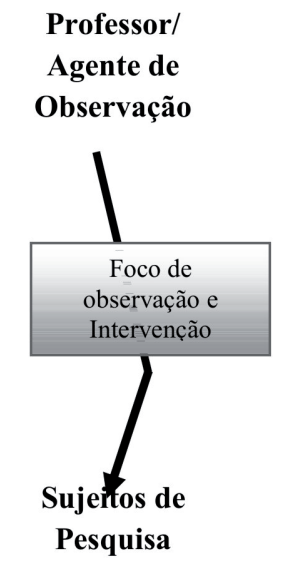

Figura 2 - Caracterização dos Agentes de Observação e dos Sujeitos de Pesquisa.

Fonte: Dados de pesquisa (NIEE/UFRGS, 2013).

A Figura 2 caracteriza os agentes de observação quanto à formação, ao tempo de docência e de aderência ao Programa UCA. O perfil diferenciado dos agentes de observação e a utilização ambiente de digital de aprendizagem como repositório e dos diários de campo imprimiram maior dinamicidade, objetividade e profundidade na coleta dos dados, permitindo uma maior sistematização para a obtenção de evidências e para a integração do observador com o contexto de pesquisa. Esse desenho metodológico destacou-se por: 1) possibilitar que o educador passasse a ser o protagonista de uma observação/pesquisa participante; 2) permitir um acesso rápido a dados de situaçóes habituais e rotineiros dos sujeitos de pesquisa; 3) facultar o acesso a informaçóes ocultas a um observador externo; 4) captar informações de esclarecimento ao acompanhar os comportamentos observados e registrados e 5) superar o principal inconveniente do observador externo, um profissional cuja presença pode provocar alteraçóes no comportamento dos observados.

Os sujeitos de pesquisa selecionados em cada escola inclusiva participante deveriam: 1) ser estudante com deficiência matriculado em turmas dos anos iniciais da Educação Básica, uma estratégia que permitiu ampliar e aprofundar o levantamento de informaçóes, possível pelo maior tempo interação professor-aluno com deficiência; 2) ter sido diagnosticado com 
Transtorno do Espectro Autista; 3) ter recebido o dispositivo móvel; 4) ter assegurada a anuência dos responsáveis por meio de um Termo de Consentimento Livre e Esclarecido.

\section{Resultados E Discussóes}

Respondendo ao desafio colocado pelo elemento desencadeador da pesquisa, as políticas públicas inclusivas em açóes estabelecidas para os contextos legislativo, regulatório e inclusivo, a análise e discussão dos dados buscaram observar aspectos relacionados à materialização da ação governamental inclusiva, em sua interface escolar e digital.

\subsection{INTERFACE -INCLUSÃO ESCOLAR: POLÍTICA NACIONAL DE EDUCAÇÃO INCLUSIVA}

Dos três sujeitos com Transtorno de Espectro Autista pesquisados, a garantia de ingresso e de permanência na sala de aula na escola inclusiva foi concretizada de forma diferenciada. Para [GF], por ser filho de uma professora em exercício de docência na instituição educativa participante, mesmo revelando um uso inconsistente na comunicação verbal e não verbal e um excessivo comportamento náo desejado no ambiente escolar - gritar, bater em si, repetir movimentos - tinha a frequência e permanência na sala de aula garantida. Se para [GF] a desordem obsessivo-compulsiva não constituiu um impedimento para o processo de inclusão escolar, para [TLC], o tempo e o espaço escolar inclusivoforam determinados pela equipe diretiva da escola e não questionado pelos responsáveis pelo estudante com deficiência.

O perfil econômico e cultural familiar diferenciado de [APL] e de [TLC] e em relação à [GF], pode ser apontado uma das possíveis explicações para justificar a naturalidade com que os responsáveis pelo estudante com deficiência [TLC] construíram junto à escola o processo de inclusão escolar do filho/estudante, principalmente quanto à permanência e ao acesso à tecnologia móvel:

[TLC] residia com o pai que era pedreiro e com a mãe, diarista, e com um irmão mais velho em uma casa em frente à escola, o que facilitava seu deslocamento. [...] $\mathrm{O}$ atendimento de [TLC] tem duração de uma hora por dia, repetido duas vezes por semana, em dias fixos: terças e quartas feiras. Na terça feira, prioriza-se a participação na aula de Educação Física. A interação da aluna era seriamente prejudicada pela ausência completa de interação comunicativa. Um aspecto muito desfavorável na aluna é a inquietação. [Ficha diagnóstica - Agente de Observação [MEAS].

[...] Os pais possuem formação superior. A mãe tem curso de Pedagogia, mas não trabalha fora para cuidar do filho. O pai é técnico de informação. A situação econômica atende às necessidades básicas. [...] A turma está dividida em grupos. [APL] foi acolhido por todos. Quando chega atrasado, todos dizem bom dia. Ele reage com alegria, entra correndo e senta no seu lugar. Gosta de estar na escola. Quando esteve doente, ficando duas semanas fora, a mãe comentou que ele pegava sua mochila, demonstrando querer ir à escola. Aceita que colegas peguem sua mão para acompanhá-lo. Quando chega à sala e está vazia, percebe-se que ele sente falta dos colegas. No parque, sente prazer em ficar na roda com os colegas, está se arriscando a andar no escorregador. [Ficha Diagnóstica-Agente de observação [TIA]. 
A situação de exclusão da aluna [TLC] foi ainda mais grave e evidente quando constatamos que o irmão mais velho, sem deficiência, tinha assegurado seu direito de acesso ao recurso computacional fora do tempo-espaço escolar. O déficit de [TLC] passou a ser a razão do impedimento, aspecto naturalizado pela família e que a colocou em posição de inferioridade em relação ao irmão, confirmada no relato da mãe: [...] Em casa, somente o irmão pode utilizar o laptop educacional. [Ficha Diagnóstica-Agente de Observação [MEAS].

Pelo contexto legislativo,a Política de Educação Especial na Perspectiva da Educação no Brasil que oficializou o reconhecimento da pessoa com deficiência, tem essa conquista fragilizada no contexto regulatório quanto ao direito de acesso e de permanência na sala de aula inclusiva para os sujeitos investigados. $\mathrm{O}$ contexto regulatório desenhado pelas instituiçóes educativas participantes da pesquisa, ao mesmo tempo em que estabeleceu para estudantes com Transtorno de Espectro Autista o estar na escola delimitado a horários reduzidos, também condicionou o processo de escolarização a ações de socialização relacionadas ao brincar social.

Comunicação, cognição e capacidade motora colocam-se com algumas das capacidades envolvidas no brincar social. Associar a socialização de estudantes com Transtornos do Espectro Autista a uma concepção simplista para o brincar na escola desconsidera que essa ação pressupóe o desenvolvimento de capacidades como a compreensão da linguagem e de regras de diálogo, aspectos fragilizados e que fazem com que esses estudantes com deficiência prefiram o brincar isoladamente.

As possibilidades de fomentar estratégias de aprendizagem para alunos com Transtornos de Espectro Autista têm na simplificação do processo de socialização seu maior impeditivo. A capacidade de envolvimento em interaçóes sociais requer uma complexa integração da linguagem verbal e não verbal, como também dos componentes cognitivos e emocionais. A socialização requer parceiros de comunicação para partilhar desejos necessidades, sentimentos e pensamentos, um compartilhamento que opera pela integração de linguagens, pelo contato ocular, pelas expressóes faciais, pelo tom de voz para comunicar mensagens emocionais, ou seja, pela relação com o outro. Como desenvolver a capacidade de socialização em estudantes com Transtornos de Espectro Autista em meio às restriçóes impostas pelas direçóes das escolas inclusivas?

O olhar obscurecido pelo laudo que demarca e rotula as especificidades desses sujeitos de pesquisa, somado a aspectos econômicos e socioculturais do contexto familiar potencializaram que a histórica lógica de exclusão de acesso aos benefícios sociais fosse mantida para [TLC] e [GF]. Para [TLC] e [GF], as políticas públicas inclusivas em sua interface escolar, materializam-se sintonizadas com o debate educativo quanto à dificuldade de se responder a esse grande desafio da Educação Inclusiva, pois, como adverte Baptista (2004, p.191, grifo nosso), "discute-se uma utopia, e não uma meta a ser implementada em um tempo preestabelecido".

Educar a diferença pela diferença impóe dificuldades para a ação educativa, uma vez que, mais do que gerar conflitos e percepçóes equivocadas, revela incomensurabilidades que extrapolam os limites da linguagem e fogem à capacidade de compreensão do discurso inclusivo contemporâneo. A inserção escolar e sociocultural ainda se concretiza pela moldura cultural 
hegemônica e homogeneizante. Reconhece-se a diversidade humana, entretanto o atendimento das especificidades de sujeitos que se comportam, como analisa Burbules (2003, p.161), fora das orientaçóes e das aspiraçóes a respeito do trabalho e do modo de vida aceito e valorizado socialmente, continua a marcar a sempre tensionada relação com a estudantes com deficiência na escola regular, forjando novas formas de exclusão.

\subsection{Interface - Inclusão Digital: Programa UCA}

O laptop educacional entregue às escolas pela ação governamental UCA ainda não trata adequadamente a questão da usabilidade e da ergonomia acessível. O exame dos dados de pesquisaconfirmou a ausência de estudos préviospara avaliar a acessibilidade e a usabilidade dos recursos tecnológicos,especialmente em relação aos estudantes com deficiência.

Uma análise técnica do equipamento (Figura 3) foi realizada por meio da aplicação de protocolos de verificação e de validação tecnológica pela equipe do NIEE/UFRGS. Os resultados revelaram aspectos restritivos do equipamento ofertado pelo programa UCA para a configuração 1:1, Classmate, dando visibilidade ao descompasso das açóes governamentais de inclusão digital em relação à Política Nacional de Educação Inclusiva.

Tela: o tamanho reduzido, ponto de maior desconforto evidenciado na utilização do equipamento. Há um espaço desperdiçado, apenas com um plástico ao redor da tela, deixando uma área bem pequena no centro da tampa. Por padrão, tem resolução $600 \times 480$, o que gera um problema já para os próprios aplicativos instalados na tecnologia móvel (programas do pacote Office e software de gerenciamento), que não

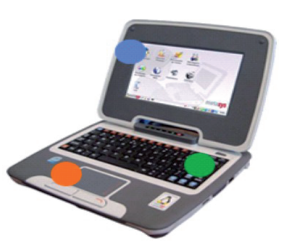
podem ser visualizados por completo. As caixas de diálogo do aplicativo ficam praticamente inacessíveis. A resolução pode ser alterada para 800 x 600 ou 1024 x 768 , mas sua utilização fica inviabilizada, pois, em virtude do tamanho da tela, os ícones e letras mostram-se demasiadamente pequenos e com efetiva perda de definição.

Teclado: pelo tamanho reduzido, digitar rapidamente, para quem está acostumado como modelo convencional, torna-se uma ação bastante incômoda. As teclas são muito próximas. Entretanto, pode ser substituído por um teclado externo com entrada USB.

Mouse: o formato Touchpad revela-se funcional, mas, para alguns tipos de deficiência, o uso prolongado pode causar fadiga muscular e desestimular a utilização do laptop educacional. Esse dispositivo de entrada de dados pode ser substituído por um mouse externo com entrada USB.

Figura 3 - Análise técnica do laptop educacional -Classmate.

Fonte: Dados de Pesquisa NIEE/UFRGS, 2013.

Os três sujeitos da pesquisa receberam o laptop educacional estabelecido pelo programa UCA. A não observação dos problemas de acessibilidade e de usabilidade da tecnologia 
móvel ofertada reduziu o sentido de pertencimento à possibilidade de ter um laptop educacional, mesmo quando já era reconhecida a inviabilidade de sua utilização para estudantes com deficiência:

[...] Nas tentativas de uso do equipamento, [TLC] não demonstrou interesse. Não utiliza o mouse touchpad. Foi necessário o uso do mouse tradicional com o auxílio da professora. Apesar da tela pequena, revela interesse pelas imagens ampliadas e, com o auxílio de pendrive, gosta de ouvir músicas [Ficha diagnóstica-Agente de Observação[MEAS].

[...] Não demonstra interesse em relação ao laptop. Apresenta dificuldade em usar o teclado e o mouse, mesmo com auxílio do monitor. [...] Esse modelo de laptop enviado à escola não auxilia [APL]. [Ficha Diagnóstica-Agente de observação [TIA].

[...] O laptop não ajuda [GF]. O computador é muito pequeno e ele não tem interesse em digitar ou tocar. Não fixa o olhar na tela. Às vezes, [GF] assiste vídeos musicais, como o da Galinha Pintadinha. [...] Muitas vezes, [GH] refuga o laptop e tenta atirá-lo no chão. [Ficha Diagnóstica - Agente de Observação [SK].

A presença do público-alvo da Educação Especial no elenco de alunos matriculados da escola regular colocou um conjunto de problemas quanto ao acesso e à qualidade de uso que não pode mais ser negligenciado pelos projetistas e designers de tecnologia educacional. O programa UCA marcou seu ingresso no cenário educacional brasileiro no mesmo momento em que as contemporâneas configurações computacionais buscavam apoiar a construção da Cultura da Participação e da Cooperação para todos (SANTAROSA; CONFORTO; MACHADO, 2014). Nessa perspectiva, como justificar a inserção de um dispositivo que inviabiliza a apropriação dos códigos para instrumentalizar estudantes para um efetivo exercício de cidadania na Sociedade do Conhecimento? Como impulsionar práticas de empoderamento para a diversidade humana com a supremacia da homogeneidade tecnológica?

As especificidades humanas apontam para a impossibilidade de uma mesma tecnologia para todos os estudantes. A universalidade deve estar garantida pelo acesso ao recurso computacional e não pela configuração tecnológica.

A tecnologia móvel continuará a ser utilizada para ocupar tempos e espaços de sujeitos que se afastam do comportamento idealizado pela escola tradicional? A opção de estabelecer com estratégias pedagógicas para alunos com Transtornos de Espectro Autista - assistir vídeos do YouTube e ouvir músicas armazenadas em equipamentos de armazenamento externos (pendrive) - evidenciam o potencial da tecnologia móvel reduzido aum dispositivo de ordenamento corporal, condizente com a meta de socialização estabelecida para esses estudantes com deficiência. A interface tecnológica passou a operar como recurso educacional para minimizar o comportamento que fugia do padrão desejado para o perfil de um aluno matriculado em uma escola regular. Pela interface da inclusão digital, afirmava-se o conceito da igualdade, todos receberam o laptop educacional, mas não o da equidade, quando a opção pela homogeneidade tecnológica desconsiderou as especificidades dos estudantes com e sem deficiência. 
Um acontecimento em um doscontextos inclusivos pesquisados ilustrouas possibilidades de aprendizagem e de desenvolvimento quando a homogeneidade tecnológica passa a ser rompida. Em um dos microcenário investigados, o sujeito de pesquisa [APL] utilizava como tecnologia móvel um tablet. Pelo perfil familiar, ambos com curso superior e o pai atuando na área da tecnologia, os responsáveis pelo estudante reconheceram o potencial do dispositivo móvel como instrumento de mediação no processo de desenvolvimento do filho, principalmentena área da comunicaçáo. Perceber os problemas de usabilidade que [APL] manifestava ao interagir com o modelo computacional do equipamento em uso pelo programa UCA fez com que a família incluísse na lista de materiais escolares do filho um iPad.

A presença do tablet na mochila de [APL] ensejou a que a equipe do NIEE inserisse novos elementos na coleta de dados e propusesse um desdobramento na investigação com a introdução de outro dispositivo móvel na escola. Um aspecto aludido de forma significativa nesse contexto inclusivo foi a ruptura com o princípio da universalidade tecnológica em programas governamentais.

\subsubsection{LAPTOP EDUCACIONAL E TABLET: UMA ANÁLISE TÉCNICA E PEDAGÓGICA}

Uma análise técnica e pedagógica para apontar as possibilidades de utilização de tablets por estudantes com Transtornos de Espectro Autista foi realizada pela equipe NIEE/ UFRGS com o objetivo de discutir a opção pela homogeneidade e universalidade da configuração tecnológica assumida por políticas brasileiras de inclusão digital para o modelo 1:1.

Tecnicamente, o laptop educacional configura-se como um computador adaptado para a portabilidade. Toda a sua funcionalidade foi herdada do computador de mesa - desktop. Mesmo com a permanente evolução dos equipamentos portáteis em relação à facilidade de uso, os laptops ainda revelam uma curva de aprendizado bastante elevada para muitos estudantes com deficiência. As observaçóes e os relatórios encaminhados para a equipe do NIEE/UFRGS sinalizaram uma interação, muitas vezes, pouco amigável.

Considerando as especificidades de estudantes com deficiência, em especial os com Transtornos de Espectro Autista, aspectos técnicos fragilizaram a mediação com o laptop educacional Classmate: o mouse e, principalmente, o teclado são interfaces de difícil compreensão e domínio, pois são dispositivos de entrada de dados com variadas possibilidades de comando e de combinaçóes.

O laptop educacional revela-se um equipamento versátil, embora, para sujeitos com deficiência, o uso do mouse e seu movimento pela tela não sejam uma forma intuitiva de interação. $\mathrm{O}$ que se subentende por intuitivo, principalmente na área de Informática, é algo inerente ao conhecimento básico humano. Um dispositivo verdadeiramente intuitivo dispensa uma grande curva de aprendizado e pode ser dominado utilizando conhecimentos simples e rotineiros. Esse aspecto coloca-se como o grande diferencial entre plataformas mais usuais para a tecnologia móvel em contexto educacional: laptop e tablet.

A interação extremamente intuitiva dos tablets dispensa a necessidade de elaborados treinamentos, pois opera por meio de um dispositivo de entrada de dados naturalmente humano, o toque dos dedos. No caso específico do [APL], a associação do movimento físico do 
mouse e de seu ponteiro no monitor apresentaram-se como algo realmente difícil. Porém, o movimento da mão sobre a tela do tablet era natural e permitia explorar com maior familiaridade as possibilidades da tecnologia móvel.

Entretanto, a justificativa de utilização de tablets relacionada à facilidade de utilização coloca-se apenas como um dos aspectos que deve ser observado. Enquanto o laptop educacional tem um sistema operacional complexo e uma interface com múltiplas escolhas e configuraçóes, o tablet subtrai da tela as decisóes complicadas. Cabe ao usuário ligar, acionar o aplicativo desejado e utilizá-lo. Não há esperas, tampouco configurações a serem definidas,fatos que para estudantes com Transtornos de Espectro Autista, são de significativa importância. $\mathrm{O}$ contato físico mais direto que os tablets proporcionam faz toda a diferença para estudantes com deficiência. Além de trazer a tecnologia para um mundo mais real e menos virtual, liberta o usuário da compreensão das funcionalidades do dispositivo para deslocar a atenção para a experiência daquilo que realmente se quer.

Em uma análise pedagógica foi possível observar que a interação de [APL] com o tablet evidenciou vantagens na sua utilização em relação ao laptop disponibilizado pelo programa UCA e outros recursos educacionais de baixa tecnologia. Os jogos digitais são bem organizados, com animação e espaço limitado. Para um estudante com Transtorno de Espectro Autista essa delimitação espacial é importante, já que imprevistos fora do espaço de atuação, como por exemplo, a quedas de peças no chão, podem mudar completamente o foco da atenção. Em jogos de encaixe, a peça, uma vez acoplada, não sairá do lugar, enquanto um quebra-cabeça de papel ou de madeira exigirá certo cuidado para que os elementos já ajustados permaneçam montados. O manuseio de peças concretas se constitui como um difícil desafio para um conjunto de pessoas com deficiências.

Para os estudantes que não apresentam comunicação não verbal, formas alternativas têm sido fortemente estimuladas pelo uso de imagens e sons, apoiando o desenvolvimento do simbolismo. Para um sujeito com Transtorno de Espectro Autista lembrar uma imagem, mesmo quando ela não está presente, é fundamental para o desenvolvimento da fala verbal. Nessa perspectiva, aplicativos educacionais disponibilizadas em tablets, pela interação mais amigável que proporciona ao usuário com deficiência, ampliam as possibilidades de diferentes recursos digitais, entre eles a utilização de programas de comunicação alternativa.

Processos de aprendizagens com o foco em jogos digitais permitem desenvolver a autonomia e a capacidade de obedecer a regras. Nas observaçóes realizadas junto a [APL], foi possível perceber a habilidade do estudante em compreender regras, sequência e formas. [APL] conseguia identificar formas geométricas, movimentar e encaixar peças com rapidez. Revelava a compreensão de regras de determinados jogos, como o dominó de triângulos e o Fruit Ninja. Conseguia organizar imagens na sequência de números e letras, mesmo não reconhecendoos grafemas e os números. O contato como esses códigos, para [APL], foi bem importante na construção do processo de alfabetização.

Os jogos pelos quais [APL] não revelava interesse eram ignorados completamente. Nessas atividades, quando o tutor da sala de aula tentava auxiliá-lo, o estudante retirava o foco de interação para, em seguida, selecionar outra. Já naqueles que despertavam seu interesse, mas 
que não conseguia jogar, [APL] solicitava o auxílio do tutor ou da professora, conduzindoa mão do medidor para o aplicativo, à espera de orientação.

No laptop educacional [APL] demonstrava uma grande dificuldade em manter o botão do mouse clicado, sem mexer a mão para arrastar,em açóes solicitadas, por exemplo, por programas de quebra-cabeça. Em um jogo de formas geométricas disponível no tablet e no laptop, para a interação no computador portátil, era preciso que [APL] clicasse no botão esquerdo e o mantivesse selecionado até o lugar de encaixe da peça para, só então, soltá-lo. Conduzir o mouse até o aplicativo desejado ainda era um desafio devido à agitação do estudante. Quando [APL] conseguia, um simples movimento com o mouse tirava a peça do lugar posicionado, fazendo com que ele recomeçasse o processo. Como isso ocorria diversas vezes, [APL] perdia completamente o interesse em prosseguir com a atividade. Utilizar o computador com mouse e teclado, para uma criança hiperativa e com coordenação motora fragilizada, como era o caso de [APL], resulta uma ação difícil e também pouco motivadora. O tablet possibilita uma manipulação direta com o jogo pelo toque do dedo.

O tablet apresenta-se como uma tecnologia móvel com uma variedade de aplicativos de fácil domínio. Portátil, oportuniza sua utilização em qualquer lugar e sem exigir uma posição rígida para interação, um fator positivo para usuários que não se mantêm sentados por muito tempo e, quando permanecem, mudam de posiçáo diversas vezes por consequência da hiperatividade. A facilidade de manuseio e a animação diante das conquistas (palmas e estrelinhas caindo) acabam tornando o equipamento atraente e motivador, instigando o estudante a manuseá-lo cada vez mais. [APL] não se detinha em um único jogo. Pela facilidade no manuseio da tecnologia e com a conquista de uma maior autonomia, [APL] passou a descobrir regras, a memorizar comandos para a apresentação de fotos,para a inserção ícones de jogos preferidos e de pastas para a sua organização e localização. Como destacou a mãe de [APL], "ele está sempre nos surpreendendo com seus recordes de pontuações" [E-mail-Mãe de [APL]].

No microcenário de investigação que contava com a participação de [APL], a homogeneidade e a universalidade que a introdução do laptop educacional do programa UCA imprimiu para a configuração tecnológica 1:1 foi rompida e outra possibilidade de mediação para o recurso computacional foi instituída. O tablet passou a fazer parte da mochila de [APL] e, assim, diferentemente dos demais alunos que necessitavam da autorização da professora para utilizar a tecnologia móvel, a liberdade de acesso tornou-se uma realidade para o aluno com deficiência. A efetiva posse da tecnologia nas mãos de [APL] fez com que as açóes mediadas pela tecnologia móvel fossem significativamente ampliadas em relação a seus colegas de sala de aula (Figura 4). Para que [APL] explorasse aplicativos digitais bastava abrir a mochila e retirar o tablet, para os demais estudantes, as condiçóes de possibilidade de acesso estavam sob o gerenciamento da professora. 


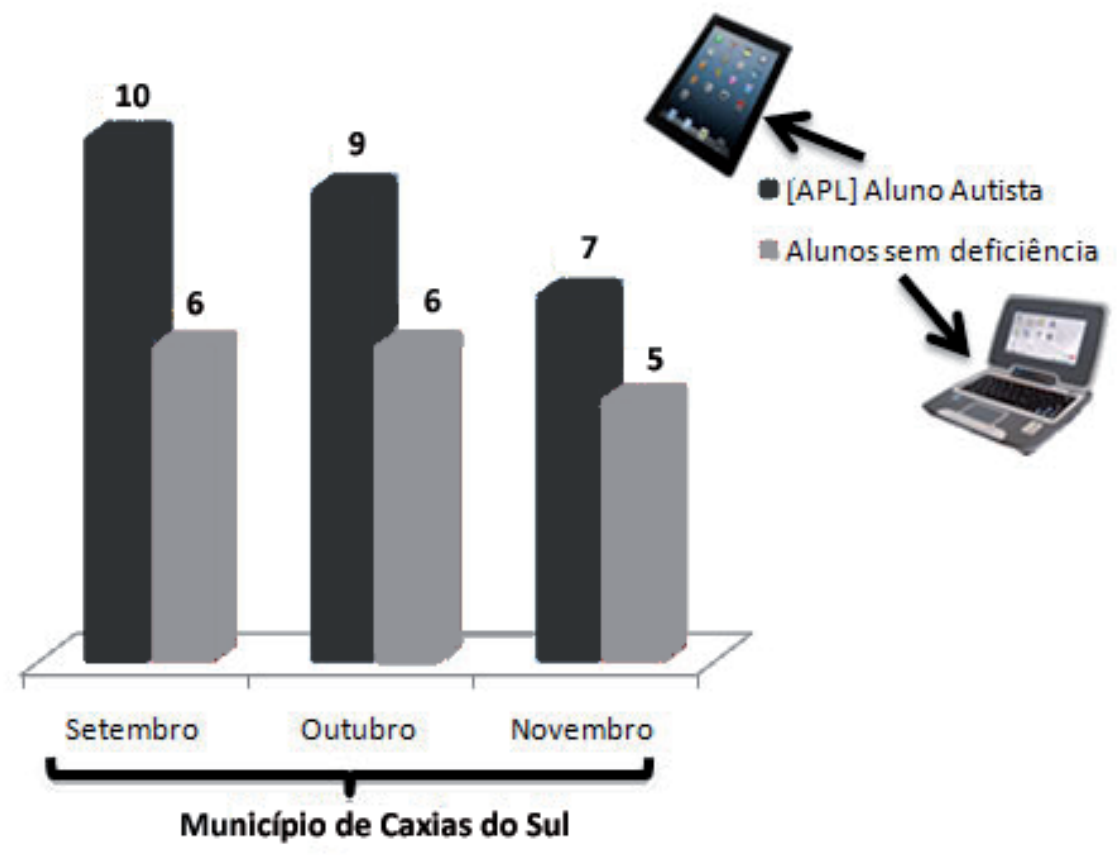

Figura 4 - Comparativos da utilização da tecnologia móvel: laptop educacional e Tablet.

Fonte: Dados de Pesquisa (NIEE/UFRGS, 2013).

O relato da professora/agente de observação sobre a interaçáo de [APL] com a tecnologia móvel confirmou uma maior vinculação com os colegas e a construção de uma autonomia na utilização do tablet. A aproximaçáo e familiaridade com as funcionalidades do dispositivo móvel, essenciais para a inserção no mundo da cultura digital, um dos princípios estabelecidos pelo Ministério da Educaçáo na elaboraçãa da ação governamental do programa UCA, começava a ser conquistada por [APL], como também a mediação tecnológica, que passou a contribuir para a sua inclusão escolar:

[...] Após a entrega do IPad, o aluno levantou a tampa e ligou com facilidade. Então, a professora abriu a atividade de desenho com lápis coloridos para ele desenhar livremente, indicando com o dedo as cores da bandeira: verde, amarelo e azul. Com toque da unha, riscou em linhas retas; usava uma cor, parava, desviava o olhar, ficava olhando para a turma. Ao comando verbal, retomava a atividade com as outras cores. A professora mudou a posição da tela de modo a ficar na vertical, na altura do olhar.Assim, houve mais tempo de atençáo na atividade. [...] Ao ouvir o som do lobo no tablet, os colegas se aproximaram e foi possível perceber que ele se sentiu bem com essa proximidade [Relatório - Agente de Observação [TIA].

A relação entre a tecnologia e [GF] foi construída sob outra lógica. A mãe de [GF], professora e profissional responsável pelo atendimento especializado na escola, não reconhecia 
no laptop educacional reais possibilidades para o desenvolvimento de sujeitos com deficiência. Como professora efetiva na instituição de ensino participante do programa UCA, não utilizava o laptop educacional, mantendo-o trancado em seu armário na escola. A professora/agente de observação [SK], muitas vezes apoiada pela equipe de pesquisa do NIEE/UFRGS, propunha diferentes estratégias de aproximação de [GF] com a tecnologia móvel. Entretanto, esses movimentos em busca da inserção de $[\mathrm{GF}]$ no universo da cultura digital foram pouco valorizados e até mesmo questionados pela mãe quando em um momento de maior agressividade do filho:

[...] A mãe de [GF] foi enfática, dizendo que o filho precisava de uma máquina maior, pois, depois que marca negativamente um objeto/situação, não esquece mais [Relatório - Agente de Observação [SK]].

\section{Conclusáo}

Projetar práticas inclusivas pela interface dos recursos digitais, referendar princípios de acessibilidade e de usabilidade são aspectos a serem observados na tomada de decisáo quanto à definição de tecnologias móveis para contextos educacionais. Ações de inclusão escolar e sociodigital não podem desconsiderar o público-alvo da Educação Especial. Alunos com deficiência estão efetivamente matriculados em escola públicas brasileiras e, por isso, com direito à utilização de todos os recursos ofertados para mediar o processo de ensino-aprendizagem.

O comportamento refratário dos sujeitos de pesquisa em relação ao laptop educacional foi constatado, o que pode ser justificado pelos problemas de acessibilidade tecnológica associada ao dispositivo móvel, muitos deles potencializados pelas especificidades do Transtorno de Espectro Autista. O laptop educacional revelou-se pouco amigável e de difícil compreensão pelo grau de abstração exigido do usuário e pela complexidade do sistema operacional, com suas múltiplas escolhas e configurações.

O fluxo do cursor do mouse na tela mostrou-se pouco intuitivo, sinalizando dificuldades na coordenação e na efetivação dos processos de seleção para usuários com Transtornos de Espectro Autista. Na interação com o tablet foi possível constatar um manuseio amigável e intuitivo, uma vez que a manipulação do objeto ocorre de forma direta, com o toque do dedo. A arquitetura dessa tecnologia permite seu uso em diferentes lugares e posiçóes, uma resposta positiva para a hiperatividade e para qualificar estratégias de mediação pedagógica.

A materialização de políticas públicas inclusivas no âmbito da inclusão escolar e digital alertou para o descompasso de açóes governamentais que compartilhavam o mesmo fim: proporcionar contextos e recursos para a inserção econômica e sociocultural de estudantes da rede pública brasileira de ensino. Touraine (2009), ao problematizar os movimentos sociais no território francês, indicou alguns impeditivos para a construção de uma sociedade que assuma seu processo educativo não como uma ação de segurança pública, mas como uma possibilidade oferecida para cada sujeito, no intuito de construir sua individualidade: 1) pela recusa da escola em considerar as singularidades psicológicas, sociais ou culturais, em nome da igualdade, o que acaba culminando de fato no favorecimento daqueles que estão ajudados a seus ambientes e na penalização daqueles que não podem se apoiar senão em suas próprias possibilidades; 2) [...] pelo fardo dos preconceitos que pesa sobre as periferias e seus habitantes, e que se constitui 
numa verdadeira rejeição de uma parcela da população em processo de integração econômica, escolar, sociocultural, apesar dos inúmeros fracassos; 3) [...] pela visão reducionista da escola como mero tempo e espaço de socialização.

O discurso presente com maior frequência nos relatos encaminhados pelas professoras que atuaram como agentes de observação exemplificam a visão reducionista da escola com um simples tempo e espaço de socialização. Isso levou a equipe do NIEE a inferir e até mesmo compreender porque o distanciamento entre a configuração 1:1 e as especificidades de estudantes com deficiência matriculados em escolas inclusivas não foi colocado como um real problema para as instituições pesquisadas. Para o público-alvo da Educação Especial, a lógica excludente do sistema educacional ofertava não uma tecnologia móvel acessível, mas a massinha de modelar, a corda, o material em EVA e, para os que revelaram uma maior dificuldade comportamental, a sedação via Ritalina.

Para o estudante $[\mathrm{APL}]$, sujeito de pesquisa que se colocava fora da histórica dívida social que pesa sobre a periferia das grandes cidades, a compra do tablet superou os problemas de acessibilidade e de usabilidade relacionados ao laptop educacional, garantindo que a mediação tecnológica pudesse ocorrer na e fora da escola. Para os que vivem o fardo da vulnerabilidade socioeconômica, o problema foi resolvido pela equipe gestora da escola, excluindo o aluno com deficiência do direito a um período maior de interação com colegas e professores, como também da possibilidade do deslocamento escola/casa/escola para a tecnologia móvel.

As instituições educativas têm papel central na promoção e na condução de práticas de empoderamento para a concretização de uma sociedade inclusiva. A fim de que essas práticas se efetivem será preciso que padróes de acessibilidade e de usabilidade passem a ser observados em relação aos produtos e aos serviços ofertados às escolas brasileiras para que os mesmos venham a configurar-se como uma possibilidade para os estudantes com e sem deficiência.

\section{REFERÊNCIAS}

BAPTISTA, C. R. Ciclos de formação, Educação Especial e inclusão. Frágeis conexôes? In: MOLL, J. (Org.). Ciclos na escola, tempos na vida: criando possibilidades. Porto Alegre, Artmed, 2004. p.191-207.

BRASIL. Ministério da Educação. Secretaria de Educação Especial. Política nacional de educação especial na perspectiva da educação inclusiva. Brasília, DF, 2007. Disponível em: <http://peei.mec.gov. br/arquivos/politica_nacional_educacao_especial.pdf>. Acesso em: 20 ago. 2014.

BRASIL. e-MAG - Modelo de Acessibilidade de Governo Eletrônico, 2011. Disponível em: <http:// www.governoeletronico.gov.br/acoes-e-projetos/e-MAG>. Acesso em: 20 ago. 2014.

BURBULES, N.C. Uma gramática da diferença: algumas formas de repensar a diferença e diversidade com tópicos educacionais. Tradução de Dinah de Abreu Azevedo. In: GARCIA, R.L.; MOREIRA, A.F.B. (Org.). Currículo na contemporaneidade: incertezas e desafios. São Paulo: Cortez, 2003.

BOURDIEU, P. A escola conservadora: as desigualdades frente à escola e à cultura. In: NOGUEIRA, M. A.; CATANI, A. M. (Org.). Escritos de educação. 2.ed. Petrópolis: Vozes, 1999.

MORAES, R. Uma tempestade de luz: a compreensão possibilitada pela análise textual discursiva. Ciência Educação, Bauru, v.9, n.2, p.191-210, 2003. 
UNESCO. Relatório global: abrindo novos caminhos para o empoderamento: TIC no acesso à informaçáo e ao conhecimento para as pessoas com deficiência/UNESCO. [livro eletrônico]. São Paulo: Comitê Gestor da Internet no Brasil, 2014. Disponível em: <http://cetic.br/media/docs/ publicacoes/8/Relatorio_Global_Unesco_FINAL.pdf>. Acesso em: 10 jan. 2015.

SANTAROSA, L.M.C.; CONFORTO, D.; VIEIRA, M.C. Tecnologias e acessibilidade: passos em direção à inclusão escolar e sociodigital. Porto Alegre: Evangraf, 2014.

SANTAROSA, L.M.C.; CONFORTO, D.; MACHADO, R.P. Whiteboard: Synchronism, accessibility, protagonism and collective authorship for human diversity on Web 2.0. Computers in Human Behavior, v.31, p.591-601, 2014.

TOURAINE, A. Pensar outra mente: o discurso interpretativo dominante. Petrópolis: Vozes, 2009.

VYGOTSKY, L. S. A formação social da mente. São Paulo: Martins Fontes, 1999.

Recebido em: 07/07/2015

Reformulado em: 10/12/2015

Aprovado em: 11/12/2015 
SANTAROSA, L.M.C. \& CONFORTO, D. 